\title{
PERVERSÃO E NORMALIZAÇÃO DAS BASES DISCURSIVAS NO EPICENTRO DAS POLÍTICAS SOCIAIS DO CENTRO RADICAL - NÃO MORRER DA DOENÇA MAS DA CURA ${ }^{1}$
}

João M. Paraskeva

Universidade do Minho, Portugal

\section{O NEO CENTRISMO RADICAL}

Tornou-se hoje em dia um saudável lugar comum a crítica contundente e inegociável às políticas sociais neo-liberais e às suas consequentes nefastas implicações nas variadíssimas esferas sociais, nomeadamente a da educação, em geral e a do currículo, em particular. A imperiosidade da necessidade de serem desnudados, desmontados e denunciados os perigos - uns mais velados que outros, diga-se - de tais políticas neo-liberais convocou a consciência política de estudiosos oriundos de vários quadrantes epistemológicos, desde a sociologia, passando pela literatura, filosofia, etc, nomeadamente Michael Apple ${ }^{2}$, Stephen Ball ${ }^{3}$, Geoff Whitty e Sally Power ${ }^{4}$, bell hooks ${ }^{5}$, Donaldo Macedo e Lília Bartolomé ${ }^{6}$, Jurjo Torres Santomé $^{7}$, José Gimeno Sacristán ${ }^{8}$, Boaventura de Sousa Santos ${ }^{9}$, José Saramago ${ }^{10}$, Michael Moore ${ }^{11}$, Eric Hobsbawm ${ }^{12}$, Landon Beyer ${ }^{13}$, entre tantos, tantos outros.

De entre estes nomes, convoco os de José Saramago ${ }^{14}$, Michael Moore ${ }^{15}$ para a consubstanciação do meu propósito neste artigo e que repousa no questionamento daquilo que de mais perigoso tem vindo a ser conseguido pelo propósito liberal, ou seja uma hábil e gradual adulteração - perversão mesmo - do verdadeiro significado e funcionamento da democracia e do Estado promovendo assim uma sociedade cada vez mais iníqua. Todavia, antes de iniciarmos a nossa análise em torno do modo como os significados de democracia e Estado têm vindo a ser gradualmente pervertidos será de bom que ganhemos tempo discorrendo um pouco sobre os contornos mais recentes do cada vez mais perigoso projecto neo-liberal.

Nenhum educador verdadeiramente preocupado com uma sociedade democraticamente justa e igual poderá ser insensível e acrítico aos sérios perigos que representa o projecto político neo-liberal para as sociedades contemporâneas. Todos nós - os que se encontram profundamente comprometidos com

\footnotetext{
${ }^{1}$ Encontro-me muito grato ao Michael Apple, Jurjo Torres Santomé e Donaldo Macedo, pelo seus indispensáveis contributos críticos a alguns dos argumentos aqui abordados.

${ }^{2}$ Apple, Michael (2003) The State and the Politics of Knowledge. New York: Routledge.

${ }^{3}$ Ball, Stephen (2001) Diretrizes Políticas Globais e Relações Polítocas Locais em Educação. Revista Currículo sem Fronteiras JulDez., 1 (29), pp., 99-116. www.curriculosemfronteiras.org

${ }^{4}$ Whitty, Geoff e Power, Sally (2002) A Escola, o Estado e o Mercado: A Investigação Actualizada. Revista Currículo sem Fronteiras Jan-Jun., 2 (1), pp., 15-40.www.curriculosemfronteiras.org

${ }^{5}$ hooks, bell (1994) Outlaw Culture. Resisting Representations. New York: Routledge

${ }_{7}^{6}$ Macedo, Donaldo e Bartolomé, Lilia. (2001) Dancing With Bigotry. Beyond the Politics of Tolerance. New York: Palgrave

${ }^{7}$ Torres Santomé, Jurjo (2001) Educación en Tiempos de Neo-liberalismo. Madrid: Morata

${ }^{8}$ Sacristán, Gimeno, José (1998) Poderes Inestables de la Educación. Madrid. Morata

9 Sousa Santos, Boaventura (2001) The Role of the Left in Post-Authoritarian Politics: Southeast Asian and Latin American Experiences. Forum. University of Wisconsin - Madison.

${ }^{10}$ Saramago, José (2003) O Nome e a Coisa. Le Monde Diplomatique. Julho, pp., 1,8-9.

${ }_{11}$ Moore, Michael (2001) Stupid White Man ... and Other Sorry Excuses for the State of the Nation. New York: Regan Books.

${ }^{12}$ Hobsbawm, Eric (1999) The New Century. In Conversation with Antonio Polito. London. Abacus.

${ }^{13}$ Beyer, Landon (no prelo) Rumos Curriculares: As Realidades e Possibilidades dos Conflictos Políticos, Morais e Sociais. In João Paraskeva (org.) Políticas Educativas e Curriculares. Um Século de Estudos Curriculares. Lisboa. Plátano Editora. Beyer, Landon (em publicação) Educar para a Justiça Social e Formas de Vida Democráticas. Revista Currículo sem Fronteiras www.curriculosemfronteiras.org

${ }^{14}$ Saramago, José (2003) O Nome e a Coisa. Le Monde Diplomatique. Julho, pp., 1,8-9.
} 
uma sociedade desprovida de qualquer espécie de segregação económica, cultural, política, ideológica, de raça, classe, género e orientação sexual - podemos não ter na mão soluções fáceis sobre o caminho a ser seguido, contudo, encontramo-nos certos pelo menos de duas coisas: o caminho para uma sociedade verdadeiramente democrática não é o que nos surge apontado pela bússola neo-liberal, nem tão pouco aceitamos pacificamente o comum senso comum, aliás bem conveniente, de uma ausência de alternativas ao projecto neo-liberal. Tal como anteriormente assinalámos, vários são os estudiosos que muito nos têm ajudado a desmontar o modo como o pensamento neo-liberal se tem vindo a implementar no campo educacional, em geral e curricular, em particular. De uma ou de outra forma, todos eles ajudam-nos - para usar a terminologia de Roland Barthes ${ }^{16}$, - a desdobrar a forma como o neoliberalismo se tem vindo a impor como bloco hegemónico dominante. Atente-se aqui ao uso do vocábulo 'bloco', crucial para entendermos como, na verdade, se constroi e desconstroi constantemente o modelo neoliberal, com o intuito de se manter como força hegemónica que transpira um triunfo deveras avassalador. Michael Apple, por exemplo, profundamente influenciado pelos 'estudos culturais' de Stuart Hall ${ }^{17}$, destaca que a compreensão do modelo neoliberal passa, entre outras coisas, por uma análise cuidada em torno das políticas instrumentalizadas quer por Ronald Reagan, nos Estados Unidos, quer por Margaret Thatcher, no Reino Unido decorria então os inícios da década de 80 do século passado. Usufruindo de um contexto internacional e nacional 'privilegiado' a um e a outro se deve a gradual implementação das políticas económicas e culturais teorizadas, entre outros, por Milton Friedman ${ }^{18}$. É este um dos colchões conceptuais em que muitos estudiosos ancoram toda a sua análise crítica em torno do movimento neo-liberal e socorrendo-se do pensamento de Gramsci desdobram a perspectiva neo-liberal como congeminada e contaminada como um poderoso bloco de [no] poder, que muito tem contribuído, não propriamente para a crise em vários sectores da sociedade, com especial destaque para a educação, mas sobretudo para a colocação do Estado como réu dessa crise.

Esta muito bem orquestrada estratégia consegue construir um senso comum hegemónico, e é precisamente no seio desta estratégia que não devemos ignorar o papel desempenhado, entre outros, pelos media ajudando dinamicamente no processo de reconstrução deste senso comum hegemónico, 'fabricando' significados particulares e obliterando muitos outros, alguns deles, até muito recentemente, quase inquestionáveis e, de alguma forma, intocáveis. Além do mais, e isto é particularmente perigoso, determinados conceitos chave e agendas que historicamente se encontravam profundamente enraizadas na verdadeira medula do corpo educacional e curricular progressista, tais como justiça social e liberdade, sujeitaram-se aquilo que me atrevo a denominar processo de (sub)(re)significação, que gradualmente tem sido capaz de reconceptualizar o verdadeiro significado assumindo um valor cultural 'mercantilizado'.

Em essência, estamos perante um processo de reconfiguração, no seio do senso comum, do verdadeiro significado de determinados vocábulos, com o intuito de operar por conseguinte, uma reconfiguração no seio do senso comum, processo esse que vai ao encontro dos desideratos da nova direita e que implica cuidadosos e intricados processos de articulação e rearticulação. Tal como Luís Gandin nos salienta de uma forma concisa, contudo incisiva, temos oportunidade de assistir como "categorias

\footnotetext{
${ }^{15}$ Moore, Michael (2001) Stupid White Man ... and Other Sorry Excuses for the State of the Nation. New York: Regan Books.

${ }^{16}$ Barthes, Roland (1987) Criticism and Truth. Minneapolis: University of Minnesota Press.

${ }^{17}$ Hall, Stuart (1988) The Toad in the Garden: Thatcherism Among Theorists. In. C. Nelson and L. Grossberg (eds) Marxism and the Interpretation of Culture. Urbana: University of Illinois Press, pp., 35-57.

${ }^{18}$ Friedman, Milton (1990) Free to Choose: A Personal Statement. New York: Harcourt. Tal como Adam Smith, Friedman acredita que todo o homem, desde que não viole as leis da justiça, deve poder perseguir livremente os seus próprios interesses pela sua livre iniciativa, colocando em competição quer a sua indústria, quer o seu capital.
} 
específicas surgem actualmente despidas dos seus significados que os relacionavam com determinadas lutas pela justiça e igualdade em geral e na educação, em particular sendo associados com categorias como "eficiência, produtividade e conhecimento como uma mercadoria" ${ }^{19}$. Neste contexto, o que verdadeiramente se encontra subjacente no vitorioso processo de reconfiguração levado a cabo pelas políticas da nova direita - não contudo sem resistências, inclusive no próprio seio do movimento neoliberal é, na verdade, uma tensão dinâmica contínua entre os complexos processo de rearticulação e desarticulação. Ou seja, os processo de articulação, que se operam com base numa tensão entre desarticulação e rearticulação, segundo Jacob Torfing permitem-nos compreender "como os artifactos culturais são sobredeterminados por determinadas ideologias políticas e ainda por determinadas identidades políticas e sociais em termos de classe, raça, nacionaldiade e género" ${ }^{20}$. Assim, a articulação é, tal como nos alerta Stuart Hall, "a forma da associação que 'pode' estabelecer a unidade de dois elementos distintos sob determinadas condições; [ou seja,] é uma relação que não é necessária, determinada, absoluta e essencial para todas as épocas". ${ }^{21}$ Assim, retomando algo que foi deixado dito anteriormente, e juntamente com Stuart Hall, importa perceber que o bloco hegemónico da nova direita foi "construído ou forjado" sob condições específicas, entre elas, os impulsos populistas e conservadores promovidos pelo Reaganismo e Thatcherismo e posteriormente desenvolvidos por George Bush e John Major.

Todavia, Norman Fairclough and Chantal Mouffe não desvinculam Tony Blair e Bill Clinton destas políticas sociais neoliberais. Ao analisar as mais recentes metamorfoses das políticas sociais neoliberais entre elas, as que tem vindo a empurrar o verdadeiro significado de democracia para um posição paradoxal uma vez que dão a perigosa ideia de que não existe outra alternativa à plataforma plutocrática neoliberal Chantal Mouffe argumenta que quer Bill Clinton, quer Tony Blair foram capazes de, com base na exacerbação neoconservadora promovida tanto por Ronald Regan, como por Margaret Thacher, 'construir' um "centro radical" ${ }^{22}$. Contrariamente ao 'centro tradicional' - "que repousa algures no centro do teatro político da 'direita' e da 'esquerda",23, o centro radical emerge como uma nova aliança que "transcende a divisão tradicional 'esquerda-direita' através da articulação de determinados temas e valores de ambos os lados promovendo uma nova síntese de significações" ${ }^{24}$. Também para Norman Fairclough este neo "centrismo radical" emerge de "uma síntese conflituosa, contudo bem conseguida, dos elementos quer da esquerda, quer da direita políticas" ${ }^{25}$. Contudo, e contrariamente a Chantal Mouffe, Norman Fairclough sublinha que estratégia deste neo 'centrismo radical' não se reduz apenas a "associar elementos da direita e da esquerda dos discursos políticos" ${ }^{26}$. Tal como argumenta, este centro radical foi realmente capaz não propriamente de se limitar a reconciliar determinados temas que eram tidos como irreconciliáveis [como também] a ir muito mais além desses temas antagónicos, trancendendo a sua própria significação”27. Não obstante as diferenças patenteadas nas análises de Norman Faiclough e Chantal Mouffe, o facto é que ambas consubstanciam a nossa tese. Ou seja, um dos trunfos das políticas sociais neoliberais repousa na sua capacidade de trabalharem constantemente o senso comum, estratégia essa conseguida através de

\footnotetext{
19 Gandin, Luís (2002) Democratization Access, Governance, and Knowledge: The Struggle for Educational Alternatives in Porto Alegre, Brazil. Madison: University of Wisconsin - Madison. Doctoral Dissertation, pp., 36-37.

${ }^{20}$ Torfing, Jacob (1999) New Theories of Discourse. Laclau, Mouffe and ZiZck. Oxford: Blackwell, p., 211.

${ }^{21}$ Hall, Stuart (1996) On Postmodernism and Articulation: An Interview with Stuart Hall. In D. Morleyand, K. Bhen (eds) Stuart Hall:

Critical Dialogues in Cultural Studies. London: Routledge, pp., 131-150, p., 141.

${ }^{22}$ Mouffe, Chantal. (2000) The Democratic Paradox. London: Verso, p., 108.

${ }^{23}$ Op. Cit., p., 108.

24 Op. Cit., p., 108.

${ }^{25}$ Fairclough, Norman (2000) New Labour, New Language? London: Routledge, p., 43.

${ }^{26}$ Op. Cit., p., 44.

${ }^{27}$ Op. Cit., p., 45.
} 
uma processo constante - não pacífico - de desarticulação e rearticulação do verdadeiro significado de determinados conceitos e práticas. Como resultado desta prática política de articulação emergem 'naturalmente' novas significações, novas relações, novas perspectivas, 'novos seres e estares', novas identidades ${ }^{28}$. De entre os conceitos que mais se têm 'sujeitado' aos perversos processo de desarticulção e rearticulação destacamos os de Estado e democracia que muito têm contribuído para a promoção de um outro senso de estar comum.

\section{OS [IN]ESPERADOS OBSTÁCULOS CHAMADOS DEMOCRACIA E ESTADO}

De entre uma vastíssima plêiade de variáveis nas quais assenta o projecto neo-liberal há duas que se têm assumido como basilares para a consubstanciação dos seus propósitos - o esbater dos verdadeiros conceitos de Democracia e de Estado, uma vez que um e outro se impõem como verdadeiros obstáculos à consecução dos desideratos neo-liberais. José Saramago ${ }^{29}$, não só nos sugere uma pista de análise interessante em torno da vituperação do conceito de democracia, como também nos abre a porta para compreendermos ainda melhor a perigosa Estadofobia que se instalou nos vários quadrantes do tecido social, Estadofobia extraordinariamente analisada, por exemplo, nas obras de Michael Moore ${ }^{30}$ e de António Barreto $^{31}$.

Numa análise crítica em torno dos calamitosos contornos que a democracia ocidental tem assumindo, José Saramago ancora a sua posição em 4 grandes eixos. Um primeiro, em que o autor, não só estabelece as diferenças entre a democracia helénica e a romana, como também estabelece os motivos pelos quais o Império Romano com toda a naturalidade perverte o modelo democrático iniciado na antiguidade helénica. Segundo José Saramago, contrariamente à democracia helénica que "pressupunha a participação de todos os homens livres no governo da cidade"32, a democracia que viria a instalar-se em Roma, pouco ou nada tem a ver com a matriz política helénica. Acrescenta o autor que "o principal e definitivo obstáculo à implementação da democracia em Roma proveio do enorme poder económico de uma aristocracia fundiária que via no sistema democrático, muito justificadamente, um inimigo directo dos seus interesses ${ }^{\text {"33 }}$. Esta destrinça bem conseguida entre o período helénico e o romano, permite-nos com alguma segurança estabelecer um paralelismo bem próximo com o momento contemporâneo em que Portugal se assume como um excelente exemplo. Nas palavras de José Saramago,

"é irresistível que [nos] interrogue[mos] se os impérios económicos e financeiros dos nossos dias não estarão, também eles, fieis à lógica exclusiva e implacável dos interesses, a trabalhar, fria e deliberadamente, para a progressiva eliminação de uma possibilidade democrática que, cada vez afastada temporalmente das suas indecisas expressões de origem, vai a caminho de um rápido estiolamento, mantida nas suas formas exteriores, mas profundamente desvirtuada na sua essência",34.

Decorre daqui e muito justificadamente que a verdadeira democracia se impõe como um extraordinário dbstáculo aos interesses económicos na mão de uma, cada vez mais pequena, minoria. E é neste primeiro eixo postulado por José Saramago que se alicerçam o segundo e os restantes. $O$ segundo eixo da análise do autor prende-se com a demagogia do voto. Segundo o autor, mais do que nos

\footnotetext{
${ }^{28}$ Laclau, Ernest e Mouffe, Chantal (1985) Hegemony and Socialist Strategy. Towards a Radical Democratic Politics. London: Verso.

${ }^{29}$ Saramago, José (2003) O Nome e a Coisa. Le Monde Diplomatique. Julho, pp., 1,8-9.

${ }^{30}$ Moore, Michael (2001) Stupid White Man ... and Other Sorry Excuses for the State of the Nation. New York: Regan Books.

${ }^{31}$ Barreto, António (2002) Tempos de Incerteza. Lisboa: Relógio D’Água.

${ }^{32}$ Saramago, José (2003) O Nome e a Coisa. Le Monde Diplomatique. Julho, p., 8.

${ }^{33}$ Op. Cit., p., 8 .

${ }^{34}$ Op. Cit., p., 8.
} 
preocuparmos com o mito do voto urge, sem demoras, problematizar a pertinência democrática de variáveis como "processos políticos de delegação, representação e autoridade democráticas"35. Com efeito, alertanos o autor para a necessidade de nos determos "um pouco a ponderar o que a nossa democracia é e para que serve, antes de pretendermos, como se tornou obsessão do tempo, que ela se torne obrigatória e universal”36. Além do mais, estamos perante uma "caricatura de democracia que, como missionários de uma nova religião, andamos, pela persuasão ou pela força, a querer difundir e instalar no resto do mundo",37, mas que nada tem a ver os davídicos princípios democráticos do período helénico, mas sim com o tal hábil e conveniente pragmatismo democrático romano. A contundência da pena do autor vai ainda mais longe, quando implicitamente reage contra a falha de sentido e memória históricos nas civilizações contemporâneas. Para o autor, as democracias a que "redutoramente chamamos de ocidentais"38, ao ancorarem-se no slogan do voto, mais não fazem do que colocar "aparências no lugar de realidades"39, uma vez que se plastificam na ideia de que "o voto do cidadão mais rico ou de pele mais clara, conta tanto nas urnas como o do cidadão mais pobre ou de pele mais escura" ${ }^{40}$. É precisamente neste eixo da sua análise em essência a demagogia de existência de uma justiça social face a uma democracia assente no voto - que José Saramago, não só desnuda a fragilidade de uma democracia que pouco mais tem para argumentar do que o voto em si, como em consequência disso denuncia as relações de concubinato entre o mercado e o Estado, abrindo assim a porta para o seu terceiro eixo de análise. As palavras do autor, dada a sua pertinência merecem destaque:

"a nenhuma comunidade mentalmente sã Ihe passaria pela cabeça a ideia de eleger indivíduos corruptos e corruptores para seus representantes nos parlamentos ou nos governos (...) nenhum escrutínio, nenhum exame microscópico dos votos anónimos seria capaz de tornar invisíveis, por exemplo, os sinais denunciadores das relações de concubinato entre os Estados e os grupos económicos internacionais cujas acções delituosas, incluindo aqui as bélicas, estão a levar à catástrofe o planeta em que vivemos (...) os povos não elegeram os seus governos para que eles os 'levassem' ao mercado, e que é o mercado que condiciona por todos os modos os governos para que the 'levem' os povos" "11.

É neste sentido que o autor destaca o facto de nada nos servir uma "democracia política que não tenha sido constituída como raiz de uma efectiva e concreta democracia económica e uma não menos concreta e efectiva democracia cultural”42. Ganha assim sentido lutar pela 'saúde' de uma verdadeira trindade democrática - política, económica e cultural - cada uma delas complementando-se entre si, até porque "a ideia de uma democracia económica, por muito relativizada que tivesse que ser, deu lugar a um mercado obscenamente triunfante, e a ideia de uma democracia cultural foi substituída por uma não menos obscena massificação industrial das culturas, esse falso - mas tão conveniente rótulo, como afinal todos os são - melting-pot, com que se pretende disfarçar o predomínio absoluto de uma delas” ${ }^{43}$. Colocada desta forma, e quanto a nós bem, as ditas democracias œidentais mais não têm feito do que gradualmente adulterar um efectivo modelo democrático que transpire justiça e equidade económica e cultural, em que os organismos eleitos refugiando-se no já visto perigoso primado puro do voto mais não conseguem do que sistematicamente se encontrarem reféns das desumanas dinâmicas do mercado. Ao questionar o conluio

\footnotetext{
${ }^{35}$ Op. Cit., p., 8.

${ }^{36}$ Op. Cit., p., 8.

37 Op. Cit., p., 8.

${ }^{38}$ Op. Cit., p., 8.

${ }^{39}$ Op. Cit., p., 8.

40 Op. Cit., p., 8.

${ }^{41}$ Op. Cit., pp., 8-9.

42 Op. Cit., p., 9

${ }^{43}$ Op. Cit., p., 9. Itálico do autor.
} 
entre o Estado e o mercado, José Saramago estabelece também o pórtico do seu quarto eixo de análise, ou seja, as ora explícitas ora implícitas dinâmicas de poder.

Como nos destaca José Saramago, "se a democracia fosse, de facto, o que com autêntica ou simulada ingenuidade continuamos a dizer que é, o governo do povo, pelo povo e para o povo, qualquer debate sobre a questão de poder deixaria de ter sentido, uma vez que residindo o poder no povo, seria ao povo que competiria a sua administração" ${ }^{44}$. No entanto, importa aqui alguma prudência quando nos deparamos com a necessidade de uma análise crítica em torno das dinâmicas de poder nas ditas democracias ocidentais. Tal como nos auxilia José Saramago, pouco sentido tem hoje falar de governo social democrata, socialista, liberal, conservador, uma vez que "em outro e inalcançável lugar está o poder, o poder real, o poder económico, esses cujos contornos podemos perceber em filigrana por detrás das tramas e malhas institucionais mas que invariavelmente se nos escapa quando tentamos chegar-lhe mais perto e que inevitavelmente contra-atacará se alguma vez tivermos a veleidade de reduzir ou disciplinar o seu domínio, subordinando-o às pautas reguladoras do interesse geral” ${ }^{45}$. Perante isto, na verdade, o esquema social ocidental "tornou-se cada vez mais numa plutocracia - governo dos ricos - e cada vez menos numa democracia - governo do povo" ${ }^{46}$. É perante este quadro social democrático ocidental perverso que José Saramago nos desafia a, mais do que renegarmos esta democracia, mais do reformarmos esta democracia, deixar de "considerar a democracia como um dado adquirido, definido de uma vez e para sempre intocável” ${ }^{47}$. Num mundo em tudo se discute menos a democracia, importa sim discuti-la com seriedade para, como propõe José Saramago, a podermos reiventar. Perante um esquema democrático em que "a massa oceânica dos pobres deste mundo [é] geralmente chamada a eleger [mas] não é nunca chamada a governar", em que o primado das lógicas do mercado e interesses privados se sobrepõem às lógicas do Estado e do bem público e comum, importa dizer com José Saramago que "não é preciso que alguém assume a tremenda responsabilidade de liquidar a democracia [uma vez que] ela se vai suicidando todos os dias ${ }^{, 48}$.

Os 4 eixos da análise que nos propõe o escritor português permitem-nos, entre outras coisas, compreender que uma verdadeira democracia - que impeça sistematicamente a cristalização de desigualdade e injustiça social - se revela como um verdadeiro obstáculo ao propósito neo-liberal. Daí que o modelo neo-liberal tenha gradualmente adulterado a construção de uma efectiva plataforma democrática com o intuito de perpetuar cada vez mais riqueza para uns poucos e cada vez mais pobreza para a esmagadora maioria. Poder-se-á assim dizer que uma coisa é o nome - democracia. Outra coisa e passese o pleonasmo, é a coisa em si que nada tem a ver com a prática que deveria estar associada ao seu mais puro conceito. Todavia, a análise de José Saramago abre-nos ainda a porta para podermos compreender algo extremamente importante para o fenómeno da escolarização. É que do 'concubinato' entre o Estado e as lógicas do mercado, o sentido efectivo democrático de bem comum se vai desvanecendo progressivamente. As análises de Michael Moore ${ }^{49}$ e António Barreto ${ }^{50}$, entre outras promovem-nos aqui ferramentas excelentes para a compreensão dos efeitos de tal concubinato no campo da escolarização, em geral e do currículo, em particular.

\footnotetext{
${ }^{44}$ Op. Cit., p., 9.

${ }^{45}$ Op. Cit., p., 9

${ }^{46}$ Op. Cit., p., 9.

47 Op. Cit., p., 9 .

${ }^{48}$ Op. Cit., p., 9 .

${ }^{49}$ Moore, Michael (2001) Stupid White Man ... and Other Sorry Excuses for the State of the Nation. New York: Regan Books.

${ }^{50}$ Barreto, António (2002) Tempos de Incerteza. Lisboa: Relógio D’Água.
} 
Segundo Michael Moore ${ }^{51}$, as políticas sociais neo-liberais têm-se traduzido, no campo da escolarização, num alarmante e consciente desinvestimento na educação pública, passando as escolas a ser 'tratadas' à imagem das lógicas do mercado promovendo-se uma promíscua relação entre o mundo da escolarização e o mercado. Esta análise é também bem patente nas obras de Michael Apple ${ }^{52}$, Donaldo Macedo e Lilia Bartomlomé ${ }^{53}$, Jurjo Torres Santomé ${ }^{54}$, José Gimeno Sacristán ${ }^{55}$ entre outros, que - e utilizando agora a expressão de José Gimeno Sacristán ${ }^{56}$ e Jurjo Torres Santomé ${ }^{57}$ - denunciam a metáfora do mercado como inadequada para o fenómeno da escolarização. Segundo Michael Moore ${ }^{58}$, a sociedade contemporânea pautada pelos ritmos e compassos do frenesim neo-liberal ao diminuir o protagonismo do Estado e do bem público e comum 'empurrou' também as escolas para uma posição ingrata. O desinvestimento intencional no campo da escolarização (campo este crucial para a consubstanciação de uma sociedade verdadeiramente justa e igual) revela-se como um processo selectivo que de todo não é aleatório. Na verdade, pese embora a política de sistemático desinvestimento que temos vindo a assistir atravesse todos os quadrantes do fenómeno da escolarização, o facto é que há determinadas áreas que tem sido 'cautelosamente' privilegiadas. A política de desinvestimento na 'coisa' pública e comum é antes de mais uma política cirúrgica. A análise de Michael Moore comprova aliás a nossa tese. Segundo o autor, é gritante o desinvestimento na formação docente, é alarmante o desinvestimento nas bibliotecas das escolas e é aberrante a "obsessão nacional pelos testes nacionais" ${ }^{59}$ como garantia de assegurar variáveis cruciais ao projecto de sociedade neo-liberal, como é o caso da "prestação de contas",60 no fenómeno da escolarização, via classe docente.

Preocupante ainda, embora previsível, é o modo como este irresponsável desinvestimento criou simultaneamente condições para a entrada de grandes grupos económicos nas escolas. Neste domínio, se não é prudente ignoramos, por exemplo, análises, como as de Michael Apple ${ }^{61}$ em torno das escolas como construtoras de uma 'audiência cativa' mercê de uma relação espúria que estabeleceram com o mercado, o facto é que a análise de Michael Moore empresta-nos também um quadro interessante em torno destas relações, relações estas que têm vindo a multiplicar-se,

"De acordo com os números do Centro de Análise da Comercialização na Educação, assistiuse a um aumento desenfreado da sua desinteressada caridade desde os anos 90 . Durante os últimos dez anos, os programas e actividades escolares registaram um aumento de $248 \%$ do apoio empresarial. Em contrapartida as escolas as permitem que as empresas associem o seu nome aos eventos escolares"

Dos vários casos documentados por Michael Moore e que permitem uma melhor compreensão da 'quasi rendição' das escolas ao mercado, em essência como consequência das tais relações de ‘concubinato' entre o Estado e o mercado (casos da 'Calvin Klein', 'Nike', 'Pizza Hut', 'General Mills',

\footnotetext{
${ }^{51}$ Moore, Michael (2001) Stupid White Man ... and Other Sorry Excuses for the State of the Nation. New York: Regan Books, pp., 85-118.

${ }^{52}$ Apple, Michael (2000) Official Knowledge. Democratic Education in a Conservantive Age. New York: Routledge.

${ }^{53}$ Macedo, Donaldo e Bartolomé, Lilia Macedo, Donaldo e Bartolomé, Lilia. (2001) Dancing With Bigotry. Beyond the Politics of Tolerance. New York: Palgrave

${ }^{54}$ Torres Santomé, Jurjo (2001) Educación en tiempos de neo-liberalismo. Madrid: Morata

${ }^{55}$ Gimeno Sacristán, José (1998) Poderes Inestables de la Educación. Madrid. Morata

${ }^{56}$ Op. Cit.

${ }^{57}$ Torres Santomé, Jurjo (2001) Educación en tiempos de neo-liberalismo. Madrid: Morata.

${ }^{58}$ Moore, Michael (2001) Stupid White Man ... and Other Sorry Excuses for the State of the Nation. New York: Regan Books, p., 109.

${ }^{59}$ Op. Cit., p., 107.

60 Op. Cit., p., 106.

${ }^{61}$ Apple, Michael (2000) Official Knowledge. Democratic Education in a Conservantive Age. New York: Routledge.

${ }^{62}$ Moore, Michael (2001) Stupid White Man ... and Other Sorry Excuses for the State of the Nation. New York: Regan Books, p., 109.
} 
'Campbell's Soup', 'Coca-Cola', 'Dr. Pepper', 'Shell', 'ExxonMobil', 'Burger King', 'Kellogs', 'Wendy's', 'General Motors') destacamos três que revelam bem o perigoso alcance de tais relações - as empresas 'General Mills' e ‘Campbell's Soup', ‘General Motors' e ‘Chanell One'. A ‘General Mills' conseguiu um acordo de 'parceria' com as escolas "recompensando as escolas que levassem os pais dos alunos a comprarem os seus produtos" ${ }^{\prime 3}$. Se neste caso a saúde financeira da escola se encontrava refém da capacidade dos agentes escolares a conseguirem mais mercado (e constante) para a 'General Mills', no caso da 'Campbell's Soup' o acordo dispensa considerandos. O programa da 'Campbell's Soup' para a educação "Providenciar as crianças dos Estados Unidos com equipamento 'gratuito', implicava que "cada escola teria direito a um computador Apple iMac 'gratuito' mediante a entrega de 94,950 rótulos de sopa da 'Campbell’,64.

Os exemplos da 'General Motors' e do 'Chanell One' são também suficientemente esclarecedores das consequências perversas das relações entre o Estado e o mercado. A 'General Motors' (bem como a 'Shell' e a 'ExxonMobil') deve ser entendia no quadro das empresas que financiam os materiais escolares, uma prática que tem vindo a aumentar desde os anos 90. Tal como destaca Michael Moore "num determinado número de escolas secundárias a disciplina de economia é 'patrocinada' pela 'General Motors'. A 'General Motors' escreve e providencia os manuais, assim como o programa da disciplina. Os estudantes aprendem, com base no exemplo da 'General Motors', os benefícios do capitalismo e como operar uma companhia - como a 'General Motors”,65. Também o exemplo da 'Chanell One' - uma análise que surge ainda mais aprofundada na obra,por exemplo, de Michael Apple - demonstra bem das intenções espúrias e implicações negativas da invasão das corporações nas escolas. Ao serem obrigados a ver 'Channel One' nas escolas (12,000 salas de aulas nos Estados Unidos vêem este canal), alunos e alunas, professores e professoras não são de todo impermeáveis às dinâmicas expostas, quer pelas notícias, quer pelos anúncios publicitários. Em essência, os exemplos da 'General Mills', da 'Campbell's Soup', da 'General Motors' e da 'Channel One' (como todos os outros), revelam bem o facto gritante de um processo ininterrupto de construção de uma audiência cativa e 'fiel', aspecto que levou Michael Apple ${ }^{66}$ a salientar os Estados Unidos da América como uma nação que vendeu os seus jovens ao mercado.

Se a análise de Michael Moore ${ }^{67}$ nos entrega inquestionáveis factos sobre os perigos da invasão do mercado nas escolas - aliás muito na sequência do que outros autores ${ }^{68}$ já haviam dito - o facto é que a de António Barreto ${ }^{69}$ permite-nos compreender os contornos do discurso falacioso que infelizmente se tornou comum senso comum em torno da incapacidade e até falência do Estado na gestão do bem público e comum e que mais não são do que o resultado de um intencional desinvestimento nas instituições estatais, onde as escolas se assume como exemplos exponenciais.

Tomando como exemplo a realidade portuguesa, António Barreto disseca a crise da administração e função pública como assente em razões de vária ordem, a saber: a "crise de crescimento; os efeitos da visibilidade pública; as consequências da comparação com a economia privada; as sequelas do desequilíbrio das finanças públicas; e a crise da mutação de natureza" ${ }^{70}$. De entre estas centramos a nossa

\footnotetext{
63 Op. Cit., p., 108.

${ }^{64}$ Op. Cit., p., 109.

${ }^{65}$ Op. Cit., p., 113.

${ }^{66}$ Apple, Michael (2001) Educating the 'Right' Way. New York: Routledge.

${ }^{67}$ Moore, Michael (2001) Stupid White Man ... and Other Sorry Excuses for the State of the Nation. New York: Regan Books.

${ }^{68}$ Apple, Michael Torres Santomé, Jurjo Gimeno Sacristán, José, Ball Stephen,

${ }^{69}$ Barreto, António (2002) Tempos de Incerteza. Lisboa: Relógio D’Água.

${ }^{70}$ Op. Cit., p., 327.
} 
atenção para as crises 'de crescimento', de 'efeitos de visibilidade pública' e as consequências da 'comparação com a economia privada'. Pelo que tange à crise de crescimento, António Barreto deixa-nos bem claro que tal crise não se deve ao facto de existirem funcionários a mais, mas sim a uma eventual má colocação dos funcionários "tanto sob o ponto de vista sectorial, como territorial" ${ }^{71}$, a uma qualificação inadequada dos funcionários de tal forma que "as funções desempenhadas não estão à altura das exigências de uma sociedade moderna"72. No que diz respeito à 'crise de visibilidade pública', António Barreto articula esta variável com o fenómeno de "politização da Administração Pública em condições de pluralidade democrática"73, um estigma que viria a promover relações difíceis entre a administração e os cidadãos em que "estes frequentemente culpam aquela por muitas das suas frustrações e carências" ${ }^{\text {" }}$, um sentimento razoável em certa medida - porque o facto é que o Estado 'não funciona' - mas que, como diz o autor roça já a medula do "preconceito" 75 pela coisa pública, e que tão bem surge desdobrado em análises como as de Michael Apple ${ }^{76}$. Com efeito, para este autor, caiu em lugar comum, a ideia de que o privado é bom e o público é mau. É precisamente este [leviano] lugar comum que promove uma injusta comparação entre o público e o privado em que o primeiro "sai sempre a perder" ${ }^{\prime 77}$. Agarrados tenazmente a variáveis como eficiência, 'accountability', eficácia, resultados, consegue-se construir um discurso flácido e populista da "inferioridade da Administração Pública"78. O Estado é visto como um empecilho à expansão do mercado. No entanto, António Barreto desmonta bem este falso discurso. Na verdade, a administração e função públicas não surgem comparadas com 'toda a economia privada', mas sim com um outro caso que se vai destacando pela 'positiva'.

Ora isto levanta-nos de imediato duas questões. Em primeiro lugar todos os dias os 'media' vão dando conta de sistemáticos encerramentos de indústrias e fábricas que em muitos casos se deve a uma gestão danosa empurrando milhares e milhares de trabalhadores e trabalhadoras para o desemprego. Por outro lado, estamos em crer que não estranharia de todo ao cidadão e cidadã comum que uma cuidada investigação em torno de determinados grupos económicos ditos como exemplos a seguir concluísse não só a existência de um tratamento preferencial e privilegiado por parte dos governos, - os tais que se escudam na legitimidade do voto - como ainda incorrecções que no tange às suas obrigações fiscais.

As análises que nos são propostas quer por Michael Moore ${ }^{79}$, quer por António Barreto ${ }^{80}$, (aliás na sequência de tantas outras efectuadas por outros estudiosos) no fundo, mais não fazem do que denunciar o sistemático e intencional desinvestimento na 'coisa' pública. Não estranha portanto que em pleno século XIX, mesmo o educador ou a educadora mais desatentos tropece em instituições educativas carenciadas aos vários níveis, que sistematicamente centenas de milhar de docentes se encontrem desempregados, que a formação profissional tenha sido 'reiventada' como um sistema de segundo plano para os 'tidos' como menos capazes, que após mais de uma década de formação contínua o sistema educativo continue sofredor de determinadas chagas seculares e sobretudo que a classe docente se encontre cada vez mais fragilizada e apontada pela sociedade como a grande culpada dos insucessos dos dunos e das alunas.

\footnotetext{
${ }_{71}^{71}$ Op. Cit., p., 327.

72 Op. Cit., p., 327.

${ }^{73}$ Op. Cit., p., 330.

${ }_{75}^{74}$ Op. Cit., p., 330.

${ }^{75}$ Op. Cit., p., 330.

76 Apple, Michael (2002) 'Endireitar' a Educação. As Escolas a Nova Aliança de Restauração Conservadora. Curriculo sem Fronteiras 2(1) Jan-Jun, www.curriculosemfronteiras.org pp., 55-78.

77 Barreto, António (2002) Tempos de Incerteza. Lisboa: Relógio D’Água.

${ }_{70}^{78}$ Op. Cit., p., 331.

${ }^{79}$ Moore, Michael (2001) Stupid White Man ... and Other Sorry Excuses for the State of the Nation. New York: Regan Books.
} 
Ainda no que tange á chaga do desemprego na classe docente, não podemos deixar de salientar os últimos dados do Instituto Nacional de Estatística, em que se constata que a nova vaga de emigrantes é liderada por pessoal qualificado. Segundo se verifica "em "mais de metade dos emigrantes portugueses em 2002 possuíam o ensino secundário e superior e cerca de $63 \%$ situavam-se na faixa etária abaixo dos 29 anos" ${ }^{\text {"81 }}$. A ditadura dos números tantas vezes tida como uma ferramenta útil para a demonstração da necessidade de 'cortes' na despesa pública reverte-se assim contra o próprio sistema. E, com isto, o país assiste à drenagem de quadros qualificados do país.

A estratégia de desinvestimento gradual - um fenómeno que cada vez se vai acentuando mais - na educação (a problemática formação inicial e contínua dos professores e das professoras, é disso um feliz exemplo) efectuada pelos sucessivos blocos de poderes que desde os finais da década de 70 e inícios da de 80 foram conseguindo ser governo, tem levado a que paradoxalmente tem vindo a ser o próprio Estado que tem pavimentado o campo para o triunfalismo do mercado. E chegamos ao ponto a que queríamos chegar com leitor. Perante o exposto, o triunfalismo 'obsceno' do mercado para usar a terminologia de José Saramago, não está dissociado da sua habilidade tanto no processo de perversão do verdadeiro conceito de democracia, quanto na diluição do protagonismo do Estado. Apesar de aqui e ali termos indo deixado, ainda que de uma forma algo topicalizada, o modo como estas estratégias desembocam no fenómeno da educação em geral e do currículo em particular, importa agora perceber como, de facto, a plataforma curricular surge também ela lesada (e produtora de lesões) no seio da própria democracia. No entanto, antes de abordarmos esta questão, convirá decerto chamar a atenção de algumas das contradições que transpiram do projecto neo-liberal, até porque o seu virtuosismo não se encontra de todo despido de complexas contradições internas.

\section{3. ... E O CURRÍCULO? CONSIDERAÇÕES FINAIS}

E o currículo? De que forma todas estas questões se reflectem na educação, em geral e no currículo, em particular? Cabe aqui bem esta questão. Tendo por base o caso de Portugal, e seguindo o provérbio popular de que o 'que não tem exemplo não tem realidade', tomemos, pois, como exemplo uma das obras que mais mediatismo teve nos últimos tempos em Portugal - "Reformar Portugal, 17 estratégias de mudança organizada" por Luís Valadares, Abel Mateus e Francisco Cabral ${ }^{82}$. Numa obra que lançada nos finais de 2002 e que em Janeiro de 2003 já ia na sua $4^{\text {a }}$ edição - os números por si falam no que tange à divulgação que a obra teve - Luís Tavares, após um intróito em que esboça as tendências e o diagnóstico da educação em Portugal, parte para aquilo que define como "Propostas Estratégicas" ${ }^{\text {" } 33}$. De entre os vários diagnósticos, destacamos dois, dados os perigosos eufemismos neles constantes.

[1]“Conquista-se o valor da diversidade, mas não o da exigência aferida na avaliação dos alunos, dos professores e do próprio sistema educativo" 84 .

[2]“Os líderes de opinião que definem as orientações da Educação em Portugal são um grupo particularmente estável ao longo de mais de 25 anos, desde os Partidos Políticos aos Sindicatos, o que facilita a estabilidade de orientações mas dificulta as mudanças estruturais. Este grupo inclui personalidades e especialistas de reconhecido mérito mas a escassa representação de certas áreas disciplinares, desde as

\footnotetext{
${ }^{80}$ Barreto, António (2002) Tempos de Incerteza. Lisboa: Relógio D’Água.

81 Jornal A Página da Educação (2003) Qualificados lideram nova vaga de emigrantes. Jornal A Página da Educação. AgostoSetembro, p., 10.

82 Tavares, Luís, Mateus, Abel e Cabral, Francisco (2002) Reformar Portugal. 17 estratégias de mudança. Lisboa: Oficina do Livro.

${ }^{83}$ Tavares, Luís (2002) Educação. Do crescimento ao desenvolvimento. In Tavares, Luís, Mateus, Abel e Cabral, Francisco (2002)

Reformar Portugal. 17 estratégias de mudança. Lisboa: Oficina do Livro, pp., 67-86.

${ }^{84}$ Op. Cit., p., 71.
} 
Ciências Exactas às Tecnológicas, desde a Economia à Gestão de Organizações, não facilita 0 desenvolvimento de culturas de intervenção que venham a ater expressão no terreno real da educação"85

Um e outro diagnóstico despertam em nós as seguintes preocupações. Como se pode falar de uma 'conquista do valor da diversidade', quando estamos perante um currículo comum? Uma das grandes contendas curriculares dos finais do século passado e inícios do actual que tem louvavelmente mastigado alguns dos curriculistas portugueses, tem sido precisamente a que opõe de um lado os defensores de um currículo comum e do outro os que entendem que o currículo comum só é útil como plataforma de discussão em torno dos saberes a serem veiculados pela escola ${ }^{86}$. Tal como tivemos ocasião de deixar dito num outro espaço, e como está mais do que demonstrado, "o currículo nacional, como documento, é um erro [uma vez que] coarcta a verdadeira essência dialéctica do processo de ensino aprendizagem" ${ }^{, 87}$. Por outro lado, o triunfalismo de um currículo comum - ainda que besuntado com os eufemismos do flexível, da autonomia, entre outros -, é ele próprio, mais do que um obstáculo à valorização da diversidade, ou o comprovativo da desvalorização dessa mesma diversidade, ou ainda, pior do que a anterior, uma estratégia de valorização de um 'determinado comum' que perpetue determinados quadros económicos e culturais em detrimento de outros.

Todavia, se o primeiro excerto se revela extremamente problemático o segundo obriga-nos a preocupações redobradas, dada a política hábil de eufemismos em que se constrói. Mas quem são os ditos 'líderes de opinião' que, como diz o estudo, 'definem as orientações da Educação em Portugal'? Os estudiosos das Ciências da Educação - agora tidos como 'líderes de opinião que definem as orientações da Educação em Portugal' jamais foram e são um 'grupo particularmente estável' e alguns deles têm precisamente clamado a ausência de uma determinada estabilidade no campo da educação, em geral e do currículo, em particular. Há muitas escolas e tendências no seio das Ciências da Educação em Portugal e as que lutam por uma mudança estrutural do sistema educativo têm sido sistematicamente silenciadas. Cabe aqui bem o diálogo que opôs, por exemplo, Maria Filomena Mónica e José Manuel Fernandes e Steve Stoer.

Por outro lado, como pode Luís Tavares falar de dificuldade em mudar estruturalmente o sistema educativo, quando ele próprio não reconhece que tal mudança estrutural passa pelo currículo? Aliás, o currículo, enquanto medula de todo o processo de escolarização, é amplamente ignorado, no referido documento.

No que tange às propostas estratégicas delineadas por Luís Tavares, algumas delas levantam-nos também sérias preocupações. Relativamente aos valores, Luís Tavares destaca a necessidade de um "espírito de solidariedade em relação àqueles que têm menos oportunidades" ${ }^{\text {" } 8}$. Importará aqui sim corrigir duas questões. Em primeiro lugar, será de bom tom não nos esquecermos as razões pelas quais numa determinada sociedade se vão perpetuando indivíduos com menos oportunidades. Em segundo lugar, os que 'têm menos oportunidades' são cidadãos e cidadãs com Direitos e não têm que se sujeitar ao 'sabor' da solidariedade dos que não têm menos oportunidades. Ainda relativamente ao valores, Luís Tavares não se refugia agora em qualquer eufemismo -desnudando assim o seu pendor pelo primado das leis do mercado -

\footnotetext{
${ }^{85}$ Op. Cit., p., 73.

${ }^{86}$ A este propósito vide Apple, Michael (1998) Currículo. Abordagens sociológicas Lisboa: Universidade de Lisboa. Paraskeva, João (2001) As dinâmicas do conflitos ideológicos e culturais na fundamentação do currículo. Porto: ASA; Paraskeva, João (2001-2002) El Curriculum como Práctica de Significaciones. Kikiriki, Cooperación Educativa, 62,63, pp., 8-16.

${ }^{87}$ Paraskeva, João (2001-2002) El Curriculum como Práctica de Significaciones. Kikiriki, Cooperación Educativa , 62,63, pp., 8-16, p., 12-14.

${ }^{88}$ Op. Cit., p., 78.
} 
quando declara como um dos valores o "espírito de iniciativa e empreendedorismo, aceitando desafios exigentes balizados por níveis aferidos internacionalmente, compreendendo as exigências da competição no âmbito da cultura de mercado em que se alicerça a Economia dos países desenvolvidos" ${ }^{\text {" }}$.

Se até aqui a análise de Luís Tavares se revela extremamente problemática, o facto é que "os 10 grandes rumos" ${ }^{, 90}$ que o autor desdobra para a educação em Portugal não são menos problemáticos. Bem pelo contrário. Dadas as limitações de espaço que se impõem a um trabalho desta natureza, trataremos aqui de contrapor apenas alguns desses rumos.

O primeiro rumo "centrar as políticas educativas na resposta objectiva às necessidades de cada aluno" "11, aviva-nos o derrotado desiderato perseguido pelos educadores do complexo movimento Progressista Educativo dos Estados Unidos nos finais do século XIX e inícios do século XX nos Estados Unidos $^{92}$. Numerosos estudos têm provado que o currículo integrado é a melhor forma de 'fazer' currículo, a melhor forma de consubstanciação da escola como uma verdadeira comunidade democrática sedimentando-se assim as bases para uma sociedade efectivamente democrática que transpire justiça e equidade social ${ }^{93}$.

No segundo rumo Luís Tavares faz a apologia, ao que chama de necessidade de 'transparência', em torno da "informação sobre os recursos, as actividades e os resultados de cada escola", ${ }^{94}$ informação essa que não deve ser, como afirma "segredo do Estado", 95 , para que pais e alunos possam 'escolher' as melhores opções. Ora, como tivemos oportunidade de referir em outros documentos ${ }^{96}$, todos nós sabemos que cada escola tem a sua estória e que por tal facto é profundamente injusto reduzi-las à acidez das tabelas 'meritocráticas'.

Ainda no seio das opções de escolha Luís Tavares declara ainda que "permitir escolhas implica o apoio social aos estudantes das áreas e grupos mais desfavorecidos (...) não só através da frequência de melhores escolas, como também através de títulos de aquisição de serviços ou bens complementares (livros, explicações, internet, etc)" ${ }^{\prime 97}$. Uma mão cheia de cuidados e interessantes estudos por esse mundo fora destrói por completo a falácia das teoria de escolha propostas por Luís Tavares ${ }^{98}$. Esses estudos, comprovam precisamente o contrário daquilo que defende Luís Tavares. Os chamados programas 'choice' e planos 'voucher' têm vindo a ser objecto de profundas críticas por parte de inúmeros estudiosos precisamente por multiplicarem as assimetrias sociais, criando um fosso entre cada vez mais poucos favorecidos e cada vez mais muitos desfavorecidos.

Para além disto, importa sim registar aqui a nossa total consternação pelo facto de surgir proposto a variável - explicações - como uma das ferramentas para um verdadeiro ensino democrático. Estamos em crer que a construção de um sistema educativo efectivamente democrático que passe pelo respeito dos

\footnotetext{
${ }^{89}$ Op. Cit., pp., 78-79.

${ }^{90}$ Op. Cit., p., 79.

${ }^{91}$ Op. Cit., p., 79.

${ }^{92}$ Kilpatrick, William (1918) The Project Method. Teachers College Record, 19, pp., 319-335.

${ }^{93}$ A este propósito ver Beane, James (2002) Integração Curricular. Lisboa: Didáctica.

${ }^{94}$ Op. Cit., p., 80.

${ }^{95}$ Op. Cit., p., 80.

${ }^{96}$ Paraskeva, João (2003) Não Morrer da Doença para Morrer da Cura. In J. Paraskeva (org.) Políticas Educativas e Curriculares. Um Século de Estudos Curriculares. Lisboa. Plátano Editora; Paraskeva, João e Morgado, José (2001) [Re]visão Curricular do Ensino Secundário. Gritos e Ecos de um Silêncio Cumprido. Porto: Asa.

${ }^{97}$ Op. Cit., p., 80.

${ }^{98}$ Lauder, Hugh; Hughes, David; Watosn, Sue; Waslander, Sietske; Thrupp, Martin; Strathdee, Rob; Simiyu, Ibrahim; Dupuis, Ann; McGlinn, Jim e Hamlin, Jennie (1999) Trading Futures. Why Markets in Education don't Work. Buckingham: Open University Press.
} 
Direitos de todos e não pela solidariedade de uns por outros passa necessariamente e precisamente pelo aniquilamento do mercado das explicações.

Por último, não deixa de ser preocupante também a 'promoção' da necessidade de "complementaridade entre Ensino Público e Privado" ${ }^{99}$ efectuada por Luís Tavares. Segundo o autor,

"A liberdade de ensino e a importância de que se reveste a promoção de iniciativas múltiplas e diversificadas valorizando a Educação não são compatíveis com concepções defensoras do monopólio estatal do ensino, as quais tendem a basear-se na crença de que só a escola pública é pura e socialmente útil, remetendo-se assim o ensino privado para mitigar, em termos supletivos o ocasionais, eventuais insuficiências da rede pública"100.

Curiosamente esta (e outras) perigosa(s) e hábil(eis) noção(ões) construída(s) do monopólio do estado na educação surge bem expressa no actual Programa de Governo - o XV Governo Constitucional Português ${ }^{101}$ - de coligação em Portugal entre Sociais Democratas e Populares. No referido programa, e na rubrica destinada ao "saneamento das finanças públicas 'para' o desenvolvimento da economia"102 o 'centro radical' português, após admitir que "a Agricultura portuguesa vive, actualmente, um dos períodos mais delicados da sua história" ${ }^{103}$, reconhece, explicitamente, entre outras coisas, a necessidade "da redução da dimensão do Sector Público, com restrição do Estado àquilo que são as suas funções fundamentais na Economia, (essencialmente reguladoras e fiscalizadoras), e da aposta decisiva no desenvolvimento do Sector Privado" 104 . Segundo os radicais centristas portugueses "a actuação do Governo na área económica terá como objectivo central a promoção da produtividade"105, até porque urge um "Estado com autoridade, moderno e eficaz" ${ }^{106}$, realidade esta até aqui inviabilizada dado o "centralismo" ${ }^{\text {"107 }}$ dito como um problema secular. São aliás estas tendências que 'não espantam' quando as vemos vertidas no domínio da educação. Também para o 'centro radical' português importa apressadamente desfazer o mito do monopólio da escola pública precisamente porque obstaculiza uma variável constitucional da liberdade. O excerto fala por si.

"O quase monopólio da escola pública que hoje existe, em todos os níveis de ensino, não é o modelo desejável. Não por ser pública, mas pelo facto de há muito estar sujeita a limitações no seu funcionamento e na sua cultura, que contrariam o princípio constitucional da liberdade de ensinar e aprender, de escolher e de aceder a um bem que toda a população portuguesa sustenta", ${ }^{\text {"108. }}$.

Na verdade,, não surpreende pois, tal como não surpreende a Santana Castilho, o "espesso manto de mediocridade" 109 que varre as variadas dermes do 'centro radical' português, no qual se reduz, diga-se intencionalmente, "o diagnóstico sobre a qualidade da abertura do ano escolar (vigente) à questão de quantas escolas começaram no dia aprazado ou quantos furos percentuais destinguem 2002 de 2003"

Perante um país com escolas em "que falta tudo, de uma simples fotocopiadora, ao papel higiénico, onde as crianças passam frio, onde ginásios e refeitórios são miragem e até casas de banho não

Apple, Michael (2001) Educating the 'Right' Way. New York: Routledge; Apple, Michael (2002) 'Endireitar' a educação. As Escolas e a Nova Aliança Conservadora. Revista Currículo sem Fronteiras Jan-Jun. 2 (1), pp., 55-78, www.curriculosemfronteiras.org

${ }_{99}$ Op. Cit., p., 80.

100 Op. Cit., p., 81.

101 XV Governo Constitucional de Portugal (2001) Programa do XV Governo Constitucional Portuguêswww.portugal.gov.pt

102 Op. Cit.

103 Op. Cit.

104 Op. Cit.

105 Op. Cit.

${ }^{106}$ Op. Cit.

107 Op. Cit.

108 Op. Cit.

109 Castilho, Santana (2003) O espesso manto de mediocridade. Jornal Público, 20 de Setembro, p., 30

${ }^{110}$ Op. Cit., p., 30. 
existem"111 se a solução para uma educação e um currículo que permita a prática de uma verdadeira democracia assente numa inegociável justiça e equidade social passa pelos 10 rumos sugeridos por Luís Tavares $^{112}$ e pelas directrizes vertidas no Programa do XV Governo Constitucional Português ${ }^{113}$, (em essência os dois documentos sobrepõem-se) como tive oportunidade de deixar dito num outro espaço ${ }^{114} \mathrm{e}$ em apelo a que todos os educadores 'contra-reformem Portugal' repito agora que "se esta é a solução para a cura, é melhor morrer da doença"115. Com efeito, quer o Reformar (a educação) em Portugal, quer o Programa do XV Governo Constitucional, mais não são do que uma "operação de cosmética barata" ${ }^{116}$. Até porque, como diz José Saramago, trazendo à colação o raciocínio do autor de 'Il Gattopardo', "demasiado sabemos que reformar algo (...) não é mais do que mudar o suficiente par que tudo se mantenha na mesma”"117.

Em essência, e na sequência do paralelismo que criamos com o raciocínio de José Saramago ${ }^{118}$, podemos adiantar que uma coisa é o nome da 'coisa', educação, em geral e currículo, em particular. Outra coisa, são as perversões que essa 'coisa' que deveria ser tida como um inquestionável bem público e comum vai assumindo e que nada tem a ver com a verdadeira génese do seu conceito.

\footnotetext{
111 Op. Cit., p., 30.

112 Tavares, Luís (2002) Educação. Do crescimento ao desenvolvimento. In Tavares, Luís, Mateus, Abel e Cabral, Francisco (2002) Reformar Portugal. 17 estratégias de mudança. Lisboa: Oficina do Livro, pp., 67-86.

${ }_{113}$ XV Governo Constitucional de Portugal (2001) Programa do XV Governo Constitucional Portuguêswww.portugal.gov.pt

${ }_{114}$ Paraskeva, João (2003) Não Morrer da Doença para Morrer da Cura. In J. Paraskeva (org.) Políticas Educativas e Curriculares.

Um Século de Estudos Curriculares. Revista Currículo sem Fronteiras www.curriculosemfronteiras.org

${ }_{115}$ Op. Cit.

116 Saramago, José (2003) O Nome e a Coisa. Le Monde Diplomatique. Julho, pp., 1,8-9, p.,9.

117 Op. Cit., p., 9.

118 Op. Cit.
} 


\title{
Contactar
}

Revista lberoamericana de Educación

\author{
Principal OEI
}

